\title{
4 The Model of Aspectuality as an Internal Temporal Structuring of States of Affairs
}

\subsection{Introductory remarks}

Human cognitive abilities allow for the conceptualisation and varied combination of pieces of aspectual information with each other and with further - i.e., temporal or modal - content, which contribute to the structuring of a state of affairs. Yet, the fourth chapter will focus specifically on a cognitive principle that plays an important, if not the central role in the aspectual structuring of a state of affairs, namely the figure-ground principle (see §3.2.3), since it is aspectuality as a crosslinguistic content category that will be discussed here in particular (which was explained in detail in Chapter 3). For this purpose, a description and classification principle of aspectual content is used, which, in accordance with the chosen onomasiological analytical perspective, is based on a general level, or even on the level of basic human cognitive ability: the delimitation principle. As will be seen, aspectuality is to be understood here as "aspectual delimitation". What this means exactly will be discussed on the following pages, where a new model of aspectuality based on this principle is systematically developed.

In order to avoid the danger lamented by various scholars, that the use of terminology established for the semasiological analysis of aspect and Aktionsart could provoke misunderstandings or a confusion of levels in an onomasiologically guided analysis, this work also proposes a new general - and homogeneous - terminology ${ }^{1}$ which reflects the chosen classification criterion of aspectuality and the delimitation principle, and which therefore seems suited to the semantic consideration of the category. In the following, therefore, we will speak less of perfective vs. imperfective, durative vs. non-durative or telic vs. atelic as, on the one hand, these traditional terms cannot reflect the new categorisation presented here, while, on the other hand, they may evoke associations that rather obstruct their correct understanding.

\footnotetext{
1 See Chapters 1 and 2 for a historical reconstruction of the traditional definitions of aspectual categories (aspect and Aktionsart), as well as the differences between unidimensional and bidimensional approaches with regards to the more general content category of aspectuality, whose respective advocators maintain a mutually critical attitude. In those two chapters, the reasons for the need to introduce new terminology for this work are also explained in more detail.
}

¿ Open Access. (C) 2019 Sarah Dessì Schmid, published by De Gruyter. (cc)BY-NC-ND This work is licensed under a Creative Commons Attribution-NonCommercial-NoDerivatives 4.0 International License.

https://doi.org/10.1515/9783110562088-005 


\subsection{Aspectual situation frames}

Aspectuality has been defined as a semantic category - as a universal content category in a relativised sense - that contains the complexity of information relating to the particular internal temporal structuring of a state of affairs. By "internal" I mean a temporal category that is independent of the relationship between the point of speech and the point of the event (i.e., non-deictic), and states of affairs are perceived as situation frames (see Chapter 3). I therefore assume that our ability to perceive and categorise allows us to structure concepts and categories into experiential contexts and also store them as such in memory. By choosing this frame-based interpretation framework, the analysis relies on the results and terminology of Cognitive Semantics. ${ }^{2}$

Once we assume that frames can be conceived as perceptual or conceptual gestalts, as forms of the human conceptual organisation of reality, we can explain states of affairs, on the one hand, as situation frames in general, and, on the other hand, aspectual contents in particular (presented in states of affairs conceived as situation frames) as figure-ground constellations. This approach relies on the description and interpretation models developed by Gestalt theory, which have the great advantage of recognising that the principle of combinability that underlies such constellations is complex and dynamic (see §3.2.3). ${ }^{3}$

I would like to claim here that the most important role in the aspectual structuring of states of affairs is played by the figure-ground process. The differently shaped aspectual frames and their elements or components which are interrelated by contiguity - and which can form subframes - are therefore interpreted as conceptual gestalts that allow for the emergence of figure-ground constellations or effects. These subframes, in turn, can produce further figure-ground effects, because a concept that is highlighted as a figure (in relation to a ground) in a given frame can in turn serve as a ground for another concept highlighted as a figure. ${ }^{4}$ The cognitive association principle of contiguity, which is central in this context, is defined - with Koch - as: ${ }^{5}$

2 As regards the motivation for choosing an interpretation framework based on the notion of frames and for a list of fundamental works on frame theory, see Chapter 3.

3 On Gestalt theory, see Köhler (1947), Wertheimer (1925), Herrmann (1976) and Metzger (1986).

4 On the general interpretation of frames and their components as figure-ground constellations, see Langacker (1987).

5 Here, see Koch (1996b, 1999a, 2001a and 2004); for classic treatments of metonymy see, e.g., Jakobson (1971 [1956]) and Ullmann (1962). On contiguity, which in the language is typically realised by metonymy, see, among others, Talmy (2000, esp. chapter 5), Fauconnier (1999), Langacker (1999), Peirsman/Geeraerts (2006a), as well as Croft's (2006) comment on the latter and Peirsman/Geeraerts' (2006b) response to Croft. 
[...] the relation existing between elements of a prototypical conceptual/perceptual frame or between the frame as a whole and each of its elements. [...] Of course, elements of a frame can, in turn, constitute (sub-)frames. (Koch 2001a, 202)

Thus, if the frame represents the entity at the macro-level, then the relations based on contiguity are the organising principle at the micro-level, which holds the individual elements of the frame together (see also Waltereit 1998, 17). If aspectuality is now defined as an internal temporal categorisation, as a temporally structuring delimitation of a state of affairs perceived as a situation frame, the relationships between the elements of that frame or between the frame as a whole and its constituent elements are also defined as relations of contiguity. Here, "temporally structuring delimitation" means, very generally, "determination" or "boundary setting", which - as an internal temporal constituting act of the state of affairs - entails the emphasis of or focussing on some temporal realities over others, which in turn recede into the background. This makes it clear that, when we speak of contiguity relationships within the frame, we refer to a very general, conceptual level. Figure (1) illustrates these particular relationships of contiguity within the frame.

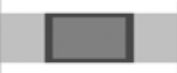

Fig. 1: Delimitation - the temporal constituting act of the state of affairs.

In Figure (1), which represents the frame as a whole, the three colours represent what can be focussed in the frame as being in the foreground or highlighted in relation to the rest (which then recedes into the background): the delimitation of the state of affairs is black, the internal structuring dark grey, the relation to the adjacency of the state of affairs light grey. By this, it also becomes evident that these elements are related to each other by contiguity and that the entire frame can only be generated on the basis of the relations existing between them. Once again, it should be emphasised that the contents distinguished here in the sense of concepts or conceptualisations and categories are to be understood as hypothetically-assumed basic units whose plausibility - but not their mental reality - can be shown by the analysis of an individual language or by language comparison. ${ }^{6}$

6 See the discussion in Chapter 3; here, esp. Aschenberg (2008), Koch (2003). 


\subsection{The delimitation principle}

The chosen criterion, which allows for the description, analysis and classification of aspectual information, therefore revolves around one principle: the delimitation principle. On the one hand, such a classification criterion seems to be sufficiently general and homogeneous in terms of semantics to take account of the needs of comparative investigations - i.e., to also serve as a tertium comparationis on a comparative crosslinguistic level. On the other hand, it is not too general that it cannot adequately grasp and describe the plurality of the aspectual contents - in the plurality of phenomena in which they become manifest in individual languages. ${ }^{7}$

What does the "delimitation principle" mean in concrete terms here? While delimiting generally means "defining”, “determining”, “demarcating”, or "setting boundaries", in the specific case of aspectuality it means "setting boundaries - initial, final, subdivision boundaries or points - in the temporal development of a state of affairs": ${ }^{8}$ Hence, the complex internal temporal structuring particular to a state of affairs is determined by the aspectual delimitation (or boundary setting); this will be illustrated in more detail in Figures (2a) and (2b), which will be commented on below. They represent states of affairs, which

7 The lack of a description of aspectual content based on a few conceptual primitives is already lamented by Sasse: "In order to understand the (language-specific or type-specific) mechanisms of interaction, it is necessary to define a number of conceptual primitives in terms of which all kinds of interaction can be described. I take it that the most important of these primitives are the different types of boundedness/unboundedness that we have come across in the course of our considerations in this paper: intrinsic bounds, arbitrary bounds, temporal bounds, bounds established by situations in a text, and perhaps others.” (Sasse 2002, 263).

8 See Talmy (2000) for an analysis - related in its theoretical approach but different in its application - of "systems" or "schemas" (“configurational structures") which represent temporal structurings of states of affairs.

Here, it shall be only briefly remarked that Talmy, in analysing the relationships between lexical forms/grammatical markers and the structures of states of affairs, distinguishes between the categories of "plexity" and "state of boundedness"; the schemas, the patterns that emerge from these categories, can then be further nested ("configurational nesting"): "Schemas from all the schematic systems and the cognitive operations they trigger can be nested to form intricate structural patterns. Specifically, schemas from the plexity and boundedness categories of the configurational schematic system can nest in this way. Nesting can be illustrated first for events in time with the verb (to) flash. The basic uniplex status of this verb is seen in The beacon flashed (once). The uniplex event can be multiplexed as in The beacon kept flashing. This can be bounded as in The beacon flashed 5 times in a row. This can then be treated as a new uniplexity and remultiplexed as in The beacon kept flashing 5 times at a stretch. And this can in turn be rebounded, as in The beacon flashed 5 times at a stretch for 3 hours.” (Talmy 2011, 628). 
in the first case cover a time span, i.e., a period of time, and in the second case do not:

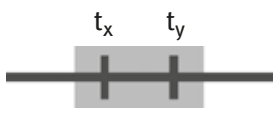

Fig. 2a: Temporal boundaries and contiguity: time span.

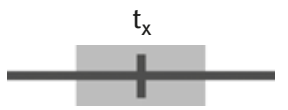

Fig. 2b: Temporal boundaries and contiguity: point of time.

In fact, when setting boundaries we have to deal with several entities related by contiguity:

- with the boundary $t_{x}$ itself or the boundaries $t_{x}, t_{y}, \ldots t_{n}$, if various are set;

- with the adjacency before and after a set boundary $t_{x}$ (i.e., $t_{a}: t_{a}<t_{x}$ and $t_{n}$ : $t_{n}>t_{x}$ ), or, in case of two boundaries $t_{x}$ and $t_{y}$, with one before $t_{x}\left(i . e ., t_{a}: t_{a}<t_{x}\right.$ ) and one after $t_{\mathrm{y}}\left(\right.$ i.e., $\left.t_{\mathrm{n}}: \mathrm{t}_{\mathrm{n}}>\mathrm{t}_{\mathrm{y}}\right) ;^{9}$

- with the interval $I=\left|t_{\mathrm{y}}-\mathrm{t}_{\mathrm{x}}\right|$, enclosed by two set boundaries ( $\mathrm{t}_{\mathrm{x}}$ and $\mathrm{t}_{\mathrm{y}}$ ), as long as they don't coincide $\left(t_{x} \neq t_{y}\right)$.

It should be added at this point by way of specification that, considered in more detail, even in the case where two boundaries $t_{x}$ and $t_{y}$ coincide (represented as $t_{x}$ in Figure (2b)), this is an interval, because strictly speaking one cannot speak of points without an extension in time. Thus, in any case, it is the interval $\left(I=\left|t_{y}-t_{x}\right|\right)$ that arises between two set temporal boundaries $t_{x}$ and $t_{y}$ and that can occur in two forms: $a)$ in the form that encloses a time $\operatorname{span}\left(t_{x} \neq\right.$ $\left.t_{y}\right),{ }^{10}$ and $\left.b\right)$ in the form that does not include a time span $\left(t_{x}=t_{y}\right)$, i.e., in the "coincidence of $\mathrm{t}_{\mathrm{x}}$ and $\mathrm{t}_{\mathrm{y}}$ ", which was mentioned above. ${ }^{11}$

Thus, what is commonly defined as a temporal point is in fact not a point but an interval, albeit the smallest possible perceptible one. But since the interval represented by each temporal $t_{x}$ is so small, it is conventionally considered

9 The adjacency also makes up the constitutive condition of a boundary.

10 This is traditionally referred to as "durative".

11 This is traditionally referred to as "punctual". 
negligible and it has become common to speak of points and/or setting of points on the temporal axis. ${ }^{12}$ It is this convention that will be followed in this work.

In the following graphic representations - which are intended to represent the elements related by contiguity participating in the process of the temporal constitution of a state of affairs - the levels of temporality and aspectuality (or "external temporality" and "internal temporality", see Comrie 1976, 5) are compared. On the one hand, this is meant to show how, in a state of affairs, temporal-aspectual contents interact with each other (how they contribute together to the overall temporal constitution of a state of affairs and how they also are often expressed by means of cumulative morphemes), while, on the other hand, it should emphasise once again that the analysis presented here is focussed on the level of aspectuality.

The first of the following representations (Figure (3)) shows the interval $\left(I=\left|\mathrm{t}_{\mathrm{y}}-\mathrm{t}_{\mathrm{x}}\right|\right)$, which is the time span arising between two different temporal boundaries $t_{x}$ and $t_{y}\left(t_{x} \neq t_{y}\right)$. " $E$ " refers to the state of affairs on the temporal level (here, Reichenbach’s typical abbreviation is used; for more details see §1.2.1):

Aspectual level

$t_{x} \quad t_{y}$

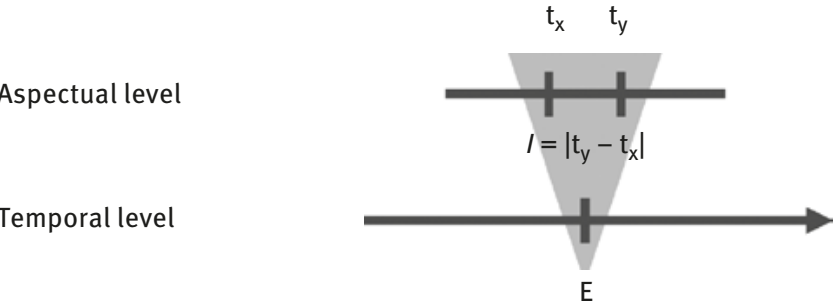

Fig. 3: Interval $\left(I=\left|t_{y}-t_{x}\right|\right)$ : time span.

Figure (3) shows examples of states of affairs of the following type, in all of which a more or less extensive period of time is recognisable:

(1) It. Leo ha mangiato [Perf. Com.] tutte le ciliegie. 'Leo ate all the cherries.'

(2) Fr. Julie parla [Pass. Sim.] de ta mésaventure avec Marie. 'Julie talked about your misadventure with Marie.'

12 Strictly speaking, it would be more correct to speak of the smallest interval of the length $\delta t_{x}$ instead of a point $t_{x}$. $\delta t_{x}$ represents the interval in which the human perception cannot distinguish two events as temporally different and is expressed as: $I=\left|\left(\mathrm{t}_{\mathrm{x}}+\delta \mathrm{t}_{\mathrm{x}} / 2\right)-\left(\mathrm{t}_{\mathrm{x}}-\delta \mathrm{t}_{\mathrm{x}} / 2\right)\right|=\delta \mathrm{t}_{\mathrm{x}}$. 
(3) Sp. Carlos comió [Perf. Sim.] muchos caracoles.

'Carlos ate a lot of snails.'

(4) Cat. Rosina va escriure [Pret. Perf. Per.] una novel-la molt maca. [anar + Inf.] 'Rosina wrote a very nice novel.'

The states of affairs presented in examples (1)-(4), which - in traditional terminology - share the feature of durativity, show in detail different aspectual patterns. Thus, examples (1), (3) and (4) represent states of affairs which traditional analysis would call "telic" and, more precisely, "resultative" ("accomplishment”), while (2) would be "atelic", i.e., "continuous" ("activity"), which will be further investigated on the following pages (see footnote 10).

The second representation (Figure (4)), on the other hand, shows the smallest possible interval $\left(I=\left|\mathrm{t}_{\mathrm{y}}-\mathrm{t}_{\mathrm{x}}\right|\right)$, arising between two set temporal boundaries $t_{x}$ and $t_{y}$ if they coincide $\left(t_{x}=t_{y}\right)$. For the sake of simplicity it has been defined as a point (see footnote 11):

Aspectual level

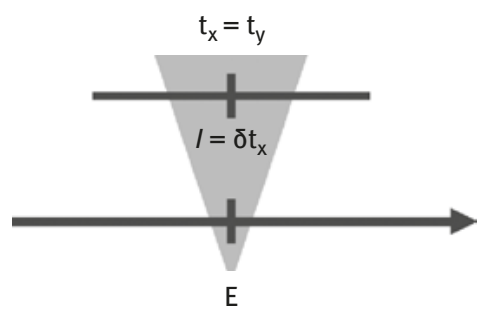

Fig. 4: Interval $\left(I=\delta t_{x}\right)$ : point of time.

Figure (4) represents examples which express states of affairs of the following type:

(5) It. Leo ha starnutito [Perf. Com.].

'Leo sneezed.'

(6) Fr. Il est arrivé [Pass. Com.].

'He has arrived.'

(7) Sp. La bomba explota [Pres.] dentro de la atmósfera terrestre sin hacer ruido.

'The bomb explodes into the Earth's atmosphere without making any noise.' 
(8) Cat. El príncep va ensorrar [Pret. Perf. Per.] la porta del castell. [anar + Inf.] 'The prince broke through the castle door.'

For the states of affairs in examples (5)-(8) - which share the so-called characteristic of "punctuality" or "non-durativity" - a similar remark is also true: they show in detail different aspectual patterns, ${ }^{13}$ which will be dealt with in greater detail on the following pages.

Hence, if it has become clear that the process of delimitation in a complex unit connects different temporal realities which are in contiguity with each other, the next step is to clarify how the mechanisms of aspectuality function in detail.

Each state of affairs conceived as a situation frame represents a complex combination of several components of aspectual information, of various realisations of aspectuality, which are also referred to here as "basic conceptualisations" or "aspectual building blocks". These are nothing other than the differently set cuts or boundaries and the resulting adjacencies and intervals, which are focussed within the temporal structuring of the states of affairs, i.e., which are highlighted compared with other pieces of information that serve as background in the complex state of affairs. Any set boundary - and this should be emphasised once more - can be considered by itself and in relation to its adjacency, for this adjacency determines and is determined simultaneously by this boundary. Thus, in each state of affairs different aspectual basic conceptualisations are combined. It should be noted, however, that the flexibility of the combinatory possibilities of the aspectual information in the state of affairs, in its concrete realisation in a context, cannot be interpreted in terms of complete arbitrariness: in other words, it is certainly not possible to combine everything with everything. As the analysis below will show more clearly, there are logical implications that do not allow the combination of some aspectual conceptualisations with others ("constraints"). The model presented here will also show what limitations the combination of the realisations of an onomasiologically perceived content category of aspectuality is subject to.

13 Thus, one would traditionally say that (5), (7) and (8) represent atelic states of affairs (more precisely, according to Smith (1991), (5) and (8) would be referred to as 'semelfactive', i.e., expressing singular, unique occurrences of states of affairs), while (6) would be defined as telic, as a state of affairs introducing a definitive change of state. 


\subsection{The three dimensions of aspectuality}

\subsubsection{External, adjacency-related and internal aspectuality}

Although each state of affairs is constituted by different, not only aspectual, components interacting with each other, the model presented below will focus on the structuring of aspectual content and will only treat further components of another (including temporal-deictic) nature if their presence in the sentence modifies the overall aspectual interpretation of the state of affairs. ${ }^{14}$

Aspectuality can be subdivided into three dimensions depending on what is emphasised in the situation frame. For, in the delimitation process, the participating elements - the boundary $\left(t_{x}\right)$ itself, the adjacencies before and after the set boundaries and the interval enclosed by two set boundaries (unless they coincide, see $\$ 4.3$ above) - are brought into focus according to three different perspectives (see Table (1) below). These are:

a) the external aspectuality of a state of affairs or its absolute delimitation: this is the determination of the state of affairs as a whole as delimited between a starting point $t_{x}$ and an endpoint $t_{y}$, and therefore completed or not delimited if such a delimitation does not exist;

b) the adjacency-related aspectuality of a state of affairs or the relevance of a state of affairs for its (direct) adjacency: this indicates whether the situation frame in any way determines or influences its subsequent $\left(t_{y+n}\right)$ and/or previous $\left(t_{x-m}\right)$ adjacency, e.g., by presenting or not its beginning or end;

14 The strict focus of the work on aspectual contents as a purely temporal structuring of states of affairs is also the reason why "reiterativity" and "habituality" are not treated separately in the model: both contain not only purely temporal (aspectual) semantic components; in both, quantity plays an essential role; in the case of the habitual, other semantic components are also important. For a critical discussion of the aspectual character of "habituality" see, among others, Carlson (2012); for a different opinion cf. Bertinetto/Lenci (2012). In some frames, the presence of, for example, temporal and/or modal adverbials plays a major role in the overall i.e., also in the particular or non-deictic, that is, aspectual - temporal structuring of the frame. This is particularly evident in comparison to cases such as It. Giulio cominciò a parlare, rompendo il silenzio che durava da ore and Giulio cominciò lentamente a parlare, rompendo il silenzio che durava da ore, where, in the second example, the presence of the modal adverb lentamente influences the temporal structure given in the first example by stretching the expressed time span; or compared to cases such as the following: It. (a) Giulio venne a trovarci, (b) Giulio venne a trovarci alle tre, (c) Giulio venne a trovarci tre volte, (d) Giulio venne a trovarci per tutta l'estate. For while (a) and (b) have an internally-temporally (i.e., aspectually) similar structure (the presence of alle tre in b) has an intensifying function), the combination with tre volte in (c) yields a reiterative reading and that of per tutta l'estate in (d) a habitual one. 
c) the internal aspectuality of a state of affairs or its further internal subdivision: here, whether or not the state of affairs is internally subdivided becomes evident; in other words, whether between $t_{x}$ and $t_{y}$ further points $t_{x 1}, t_{x 2}, \ldots t_{x n}$ are identifiable, in which the interval $I=\left|\mathrm{t}_{\mathrm{y}}-\mathrm{t}_{\mathrm{x}}\right|$ can be structured. ${ }^{15}$ It is therefore a question of whether the state of affairs is pluriphasic or monophasic.

Each of these dimensions is perceived as a figure in relation to the others which are the corresponding ground. In the chosen framework of this work and in accordance with the principle of aspectual delimitation, the definition (1) of aspectuality given in $§ 3.2 .5$ can be specified as follows:

Aspectuality expresses the possibilities of external (absolute delimitation or non-delimitation), adjacency-related (adjacency relevance or non-adjacency relevance) and internal (subdivision or non-subdivision) temporal structuring of a state of affairs.

Definition 2: Aspectuality and its dimensions

Table (1) illustrates the three subdivisions of aspectuality by showing, on the one hand, what is considered from the chosen perspective (black in the drawing) and, on the other, by illustrating that each focussing is only possible by referring to a background (grey in the drawing). The state of affairs can be interpreted in its entirety, but is constituted only in the particular combination of its individual parts, the aspectual basic conceptualisations, which complement and enable each other as foreground and background. Analytically, these parts can be viewed in isolation, as intermediaries of aspectual content only in the function of their mutual relationship within the state of affairs, and on the common background of the state of affairs (abbreviated as SA in the table):

Tab. 1: The three dimensions of aspectuality.

\begin{tabular}{lll}
\hline$\nabla \quad \nabla$ & $\nabla$ & \multicolumn{1}{c|}{$\boldsymbol{\nabla}$} \\
\hline \multicolumn{1}{|l|}{$\begin{array}{l}\text { EA - External Aspectuality } \\
\text { (delimitation of an SA) }\end{array}$} & $\begin{array}{l}\text { AA- Adjacency-related } \\
\begin{array}{l}\text { Aspectuality } \\
\text { (adjacency relevance of an SA) }\end{array}\end{array}$ & $\begin{array}{l}\text { IA - Internal Aspectuality } \\
\text { (subdivision of an SA) }\end{array}$ \\
\hline
\end{tabular}

15 Of course, this also applies to an externally non-delimited state of affairs, i.e., a state of affairs in which neither starting nor endpoint $t_{x}$ and $t_{y}$ are highlighted. 
As regards external aspectuality (EA), here the extent of the state of affairs is focussed as a whole, as a unit delimited or not delimited between a $t_{x}$ and $a t_{y}$. The figure here is therefore the delimitation of the state of affairs (black in the drawing), while the subdivision of the state of affairs as well as its relation to its adjacency and other states of affairs recede into the background (marked in grey).

In the case of adjacency-related aspectuality (AA) the focus is on the adjacency relevance of the state of affairs, i.e., whether and how it structures - as its beginning or end - a state of affairs of its adjacency and, therefore whether or not it is relevant for the temporal constitution of its adjacency, and, if so, in what form. The figure here is the relationship between the state of affairs delimited by $a t_{x}$ and $a t_{y}$ and its adjacency (black in the drawing), while the delimitation itself and the structuring of the state of affairs recede into the background (marked in grey).

As far as internal aspectuality (IA) is concerned, the internal structure of the state of affairs is focussed independently of its consideration as a whole, i.e., its subdivision or non-subdivision into phases, into intervals, by the setting of possible temporal boundaries (different $t_{i}$ ). The figure here is the structuring of the considered state of affairs (black in the drawing) independent of its delimitation and its relation to its adjacency and to other states of affairs, which then represent the ground (marked in grey).

However, renunciation of an ontological-categorial, verb-classificationbased conception of aspectuality certainly does not mean that the model developed here disregards criteria that structure states of affairs purely in terms of time. Rather, it means - and vice versa - the exclusion of criteria from this analysis which do not concern the temporal level. ${ }^{16}$ Consequently, we neither speak of "telic" or of "atelic" states of affairs here, nor is this criterion considered in any of the analytical categories of this study. ${ }^{17}$ We simply forego telicity understood as a classification criterion for states of affairs with an inherent natural (or intended) endpoint (see, e.g., Depraetere 1995). We do this not only because such a view is in fact not just a criterion that relates to the ontological-

16 For a criticism of Vendler in this sense see also Verkuyl (1993, esp. 33ff.). In contrast to the approach advocated here, Verkuyl opts for a strictly mathematical conception of compositionality as the principle of the connection of aspectual information.

17 At the same time, this makes it possible - even though in a radical way - to avoid another important criticism levelled by advocators of bidimensional approaches: the complaint - as discussed in more detail in Chapter 2 - that the criteria of delimitation and telicity are confused and mixed. See, among others, Krifka (1998) for an analysis of a differently conceived telicity: he identifies it more with the Depraeterian delimitation, since he is also convinced that "the nature of the endpoint does not affect the points to be made" $(1998,197)$. 
categorial level of verbs, but also because it is one that does not just encompass purely temporally structuring components: telicity ${ }^{18}$ is about the nature (and not just about the temporal structure) of these endpoints or delimitations. ${ }^{19}$ When we speak of "adjacency-related aspectuality" here, this must in no way be confused with telicity: (final) adjacency-related aspectuality is concerned with the relevance of a state of affairs expressed by a predicate and other components for its (previous) adjacency, and not with reaching an endpoint towards which the predicate itself strives.

In the model developed here, therefore, external aspectuality (EA) or delimitation includes the criterion of duration. For, by definition, time is duration: it consists not only of a succession of points of time $\left(t_{1}, t_{2}, t_{3}, \ldots t_{n}\right)$ and possible starting and endpoints $\left(t_{x}\right.$ and $\left.t_{y}\right)$, but also necessarily the time spans between them (which are again subdivisible, but do not consist merely of points). Thus, if states of affairs that are delimited externally by two points of time, $t_{x}$ and $t_{y}$, which do not coincide, they are states of affairs with a duration; but also externally not delimited states of affairs, i.e., states of affairs which are not delimited externally by two coinciding points of time $t_{x}$ and $t_{y}$ and necessarily consist of several points of time $\left(t_{1}, t_{2}, t_{3}, \ldots t_{n}\right)$ must have a duration. $^{20}$

18 At least in some of the literature on telicity. As noted in the previous footnote, in his interpretation of telicity Krifka distances himself from this widespread view.

19 If we consider so-called telic verbs not per se, but rather in their concrete realisation in the state of affairs, we can see that only those states of affairs can be called "telic" which have an aspect marking of completion: It. (a) La nave approdò [perf. past marking] vs. (b) La nave approdava [imperf. past marking]. In the state of affairs presented in (a) the Aktionsart expressed by the verb could easily be defined as telic; but whether the telos of the state of affairs shown in example (b) is reached remains open, so that, taking a bidimensional approach, we are forced to speak of an abolition of the telos, of "interferences between aspect and Aktionsart" (see Dowty (1977) on the known paradox of the imperfective). Often this argument is used to emphasise the need to distinguish between "(un) boundedness" and "(a)telicity" (in other words, between aspect and Aktionsart), see, in particular, Declerck (1989) and Depraetere (1995). As regards the criterion of (non-)delimitation, states of affairs are classified on the basis of "actual (concrete, realised in context, in the sentence) temporal delimitation"; as regards the criterion of (a)telicity, states of affairs are classified on the basis of "potential endpoints". Croft (2012) introduced in this sense the distinction between "temporal boundedness" ("t-boundedness") and "qualitative boundedness" (“q-boundedness").

20 Only if $t_{x}$ and $t_{y}$ are identical, i.e., if they coincide, are they punctual states of affairs, i.e., those that we can define as having no duration; cf. in this regard $\S 4.3$ above. 
By contrast, adjacency-related aspectuality (AA) encompasses the criterion of ingressivity/resultativity and the change of state in time. If the state of affairs delimited between $a t_{x}$ and $a t_{y}$ is relevant for the temporal constitution of its subsequent adjacency, this means that a focus is being made, based on the fact that the state of affairs serves as the beginning to its adjacency: in Ger. Marie-Rose fing an zu singen ('Marie-Rose began singing'), the beginning of the singing influences its subsequent adjacency by establishing its beginning (Marie-Rose started singing, and probably she continues to sing). On the other hand, when the state of affairs is relevant for its previous adjacency, it structures its end: in Ger. Marie-Rose kam zu Hause an ('Marie-Rose arrived home'), the arriving home influences its previous adjacency by presenting it as its end (Marie-Rose has reached the house and is no longer on the way home). ${ }^{21}$

Finally, internal aspectuality (IA) includes the criterion of dynamicity/stativity. ${ }^{22}$ Only if it is possible to set further subdivision points or boundaries in the temporal structuring of the state of affairs, is there the possibility of variability in time, since this consists in the change of state, the formation and ending of intervals, and thus a temporal boundary setting. In other words, where no discrete, qualitatively different temporal subintervals can be considered, there can be no change in time (and vice versa). Thus, monophasic states of affairs - whose internal structure is homogeneous and is not internally temporally further subdivided (into further points $t_{x 1}, t_{x 2}, \ldots t_{x n}$, into which the interval $t_{x} \ldots t_{y}$ could be subdivided) - are static, while pluriphasic states of affairs - whose internal structure is temporally further subdivided - are dynamic.

\subsubsection{Realisations of the three dimensions of aspectuality}

The three above-mentioned dimensions of aspectuality - external, adjacencyrelated and internal - can in turn be subdivided into a limited number of subtypes in which they are realised in an individual frame: the aspectual basic conceptualisations. There are also cases in which individual aspectual dimensions cannot be identified as delimited or not delimited (i.e., as externally delimited or not, as adjacency-relevant or not adjacency-relevant, as subdivided or not subdivided), since they are not delimitable. Table (2) summarises these basic conceptualisations schematically to give a first overview. A detailed

21 Naturally, $t_{x}$ and $t_{y}$ can also coincide and it can be a punctual state of affairs.

22 In research on aspect and Aktionsart it is common to distinguish not just between "telic" and "atelic", "durative" and "non-durative", but also "static" and "dynamic" states of affairs. 
analysis of the possible realisations of the three aspectual perspectives (as well as the cases resulting from the impossibility of combining certain aspectual information) will be presented on the following pages using different examples, firstly by considering these realisations in isolation, then in their combination in different states of affairs. The abbreviations used are also explained in detail below:

Tab. 2: Aspectuality - overview of the basic conceptualisations.

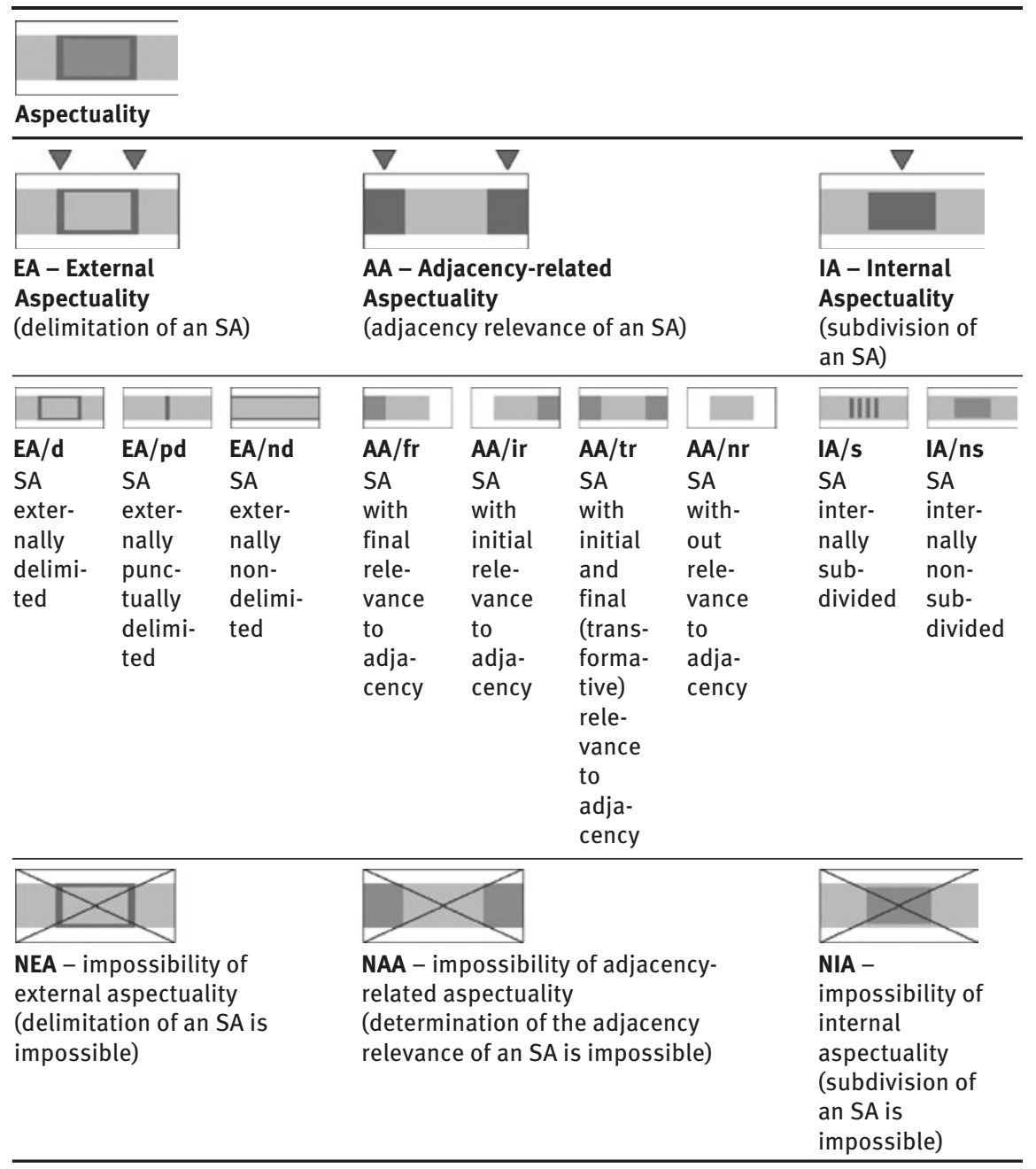




\subsubsection{External aspectuality - delimitation of a state of affairs}

Before an analysis of the various realisations of aspectuality can be made in detail, it should be emphasised again that it is actually impossible to give examples of individually isolated aspectual perspectivisations in a situation frame, since the aspectual organisation of a state of affairs is made up of a combination of the different perspectives of aspectuality. ${ }^{23}$ Therefore, it should be clarified once again that the examples given below for the individual perspectives of aspectuality serve only for analytical presentation, which should lead to a better understanding of the model developed, and do not correspond to an absolute reality. Indeed, in aspectual information, several dimensions of aspectuality are always connected with each other, of course with different emphases: the temporally structured state of affairs unanimously represents a complex constellation of elements related by contiguity (the basic conceptualisations, which each represent realisations of the three dimensions of aspectuality), which is reached only at the level of the situation frame. Thus, for the analysis of the examples given here a focus is set, and the other dimensions are initially excluded. Consequently, some examples appear in several places: they are then used to exemplify the realisation of a particular aspectual perspective that occurs in the frame.

In the case of external aspectuality (EA), the focus lies on the delimitation of the state of affairs, while its subdivision and adjacency relevance recede into the background. It can have three realisations:

- A state of affairs may be externally delimited and can be extended (EA/d); in this case it is a delimited state of affairs $\left(t_{x} \ldots t_{y}\right)$ whose initial boundary does not coincide with its final boundary $\left(t_{x} \neq t_{y}\right)$.

- A state of affairs can be externally delimited and cannot be extended, i.e., it is punctual (EA/pd); in this case it is a delimited state of affairs $\left(t_{x} \ldots t_{y}\right)$ whose initial boundary coincides with its final boundary $\left(t_{x}=t_{y}\right)$.

- A state of affairs cannot be externally delimited (EA/nd); in this case, it is a non-delimited state of affairs $\left(t_{1}, t_{2}, t_{3}, \ldots t_{n}\right)$, thus it has no initial $\left(t_{x}\right)$ and no final delimitation $\left(\mathrm{t}_{\mathrm{y}}\right)$.

The following Table (3) illustrates the different realisations of EA (what is focussed, i.e., the delimitation of the state of affairs, is marked in black in the

23 The basic conceptualisations are not only combinable with each other on the higher level of the entire state of affairs (and combined in the respective currently-expressed state of affairs), but can then also be perspectivised further. This means that they can also be further focussed within the state of affairs (this will be discussed in more detail later, especially in Chapter 6). 
first row and dark grey in the second row of the table; what functions as background is in both rows shown in light grey):

Tab. 3: External aspectuality.

EA
$\begin{aligned} & \text { EA/d } \\ & \text { delimitation of a state of affairs (SA) }\end{aligned}$
$\begin{aligned} & \text { externally delimited SA } \\ & \text { (with delimitation of the }\end{aligned}$

As indicated above, however, in the case of EA there is also another possibility that does not correspond to any of the basic conceptualisations so far presented but concerns a more abstract level of (non-)delimitability (see the last row in Table (3), but also in Table (2)). There are special aspectual constellations, in which, for logical reasons, certain combinations of aspectual information are excluded, and for which it is therefore not possible to make a statement regarding EA. ${ }^{24}$ These are cases that may be referred to as externally non-delimitable, or cases of impossible external aspectuality and external non-delimitability (NEA). These are, for example, states of affairs in which there is a semantic combination with a high degree of genericity and an absence of any aspectual information concerning absolute delimitability, so that we have an externally

24 This level is not to be confused with what Smith (1991) calls "neutral viewpoint aspect" (see Chapter 2). 
atemporal, and therefore absolutely valid, level, as is evident in the following example, commented on in more detail in $§ 4.4 .3 .4$ :

(9) Fr. Les hommes sont mortels.

'Men are mortal.'

Of the various examples (and example types) of realisations of external aspectuality (EA) that could be given - and of the impossibility of external aspectuality or external non-delimitability (NEA) - only a few will be presented and briefly commented on in what follows.

All of the following examples represent possible states of affairs conceived as situation frames in which different types of aspectuality can be identified; this applies not only to the examples in which EA is presented, but also to those that show all the other realisations of aspectuality, which are analysed in the sections below.

These are examples, commented on side by side, a) of all four Romance languages examined here, in which b) aspectuality is expressed both by lexical and by grammatical means, and which, moreover, c) mostly have different tenses.

This is not in line with the usual classification and treatment of states of affairs in which categories of aspect and Aktionsart are distinguished, and this is intentional for several reasons, consistent with the theoretical approach underlying this work.

First of all, the parallel treatment of examples from several Romance languages serves to show the variety of formal means available to them to express aspectual content. This is intended to show that different languages can have different means for expressing the same aspectual content, and also that one and the same language can have several options for doing so. ${ }^{25}$

Furthermore, presentation of these differences makes it clear that there is no inevitable correspondence between a particular realisation of aspectuality and a precise morphological marking or a particular type of predicate. We cannot say, for example, that only the verb forms traditionally labelled perfective - such as the Passé Simple and the Passé Composé in French, or the Passato Remoto and the Passato Prossimo in Italian - express the presence of an external delimitation of the state of affairs, as this can be expressed by other tense forms (the present tense, for example) or by lexical or lexical-syntactic forms (such as adverbs or

25 For example, It. Ho appena mangiato [tense marker Passato Prossimo + lexical, adverbial element] vs. Fr. Je viens de manger [periphrastic construction: venir + de + Inf.]; but in French there are some alternatives for Je viens de manger: J'ai juste terminé de manger vs. Je termine en ce moment/à l'instant de manger. Similar possibilities exist in Italian. 
combinations of verb stems with special arguments). ${ }^{26}$ This makes it very clear that the model developed here is situated on a radically different, onomasiological level, and that there is no direct correspondence between the three dimensions of aspectuality in their various realisations and the categories of aspect and Aktionsart as they are understood traditionally and from a semasiological point of view. Thus, it would not be possible, for example, to trace back - or, so to speak, to translate - aspect oppositions in general to external aspectuality and Aktionsart in general to internal aspectuality.

Finally, the comparative presentation serves once more to show that a large number of elements contribute to the overall interpretation of the situation frame.

\subsubsection{Externally delimited states of affairs (EA/d)}

Situation frames exhibiting external delimitation can be found in the following examples:

(10) It. Leo ha giocato [Perf. Com.] una partita a calcio con i suoi amici. (EA/d) 'Leo played a football game with his friends.'

(11) Fr. Julie a mangé [Pass. Com.] une pomme en trois minutes. (EA/d) 'Julie ate an apple in three minutes.'

(12) Sp. Marta no me habló [Perf. Sim.] durante mucho tiempo. (EA/d) 'Marta hasn't talked to me for a long time.'

(13) Cat. Fa una setmana que no escolto [Pres.] la ràdio. (EA/d) 'I haven't listened to the radio in a week.'

When considering aspectuality from an external perspective, as it appears in the states of affairs expressed in (10)-(13), it is to be noted that all the

26 An example such as It. Avrei voluto un morso di quel bel cornetto al cioccolato che aveva comprato Daniel, ma l'ha mangiato Leo shows perfectly the tendency of the Romance languages to express aspectuality by grammatical means. Here, ha mangiato is the 3rd Pers. Sing. of the Passato Prossimo or, following the terminology of Bertinetto (1986), the Perfetto Compiuto; the morphological (inflectional) marking cumulatively expresses here +tense/past, +mode/indicative and +aspect/perfective (as it is defined in traditional terminology). However, comparison of examples such as Leo viaggia da Roma a Parigi and Leo viaggia volentieri shows very well that such contents cannot be expressed by grammatical means only: here, the presence of different lexical and non-grammatical elements (especially viaggiare da Roma a Parigi) exerts an influence on the external aspectuality. 
examples are cases of EA/d, i.e., aspectually externally delimited states of affairs where $t_{x} \neq t_{y}$ is true, which, in other words, represent an interval $I=\mid t_{y}-$ $t_{x} \mid$ that human perception can recognise as a time span. Analysing (10) and (11) in more detail, we can say that the states of affairs that Leo had a football game with his friends and that Julie ate an apple in three minutes are each delimited by two temporally non-coinciding boundaries $t_{x}$ and $t_{y}$ : by a starting point $t_{x}$ (the moment when the referee's whistle blew to start the game or Julie's first bite into the apple) and an endpoint $t_{\mathrm{y}}$ (the moment the referee blew the final whistle or Julie's last bite from the apple). We can also describe (12) and (13) in a similar way: the interval ${ }^{27}$ between the moment $t_{x}$ when Marta started no longer talking to me and the moment $t_{\mathrm{y}}$ when she stopped doing so, and that between the $\mathrm{t}_{\mathrm{x}}$ (= one week ago) when I stopped listening to the radio and $t_{\mathrm{y}}$ (= the moment of speaking) when I claim this, are both intervals that are perceived as a time span.

\subsubsection{Externally punctually delimited states of affairs (EA/pd)}

The following will be considered examples of externally punctually delimited states of affairs (thus, where $t_{x}=t_{y}$ ):

(14) It. All'una finalmente Julia si è addormentata [Perf. Com.]. (EA/pd) ${ }^{28}$ 'At one o'clock, Julia finally fell asleep.'

(15) Fr. À cinq heures Daniela frappe ${ }^{29}$ [Prés.] à la porte; Julien l'attendait. (EA/pd)

'At five o'clock Daniela knocked on the door; Julien was waiting for her.'

27 The presence of mucho tiempo in example (12), and of fa una setmana in (13) emphasises the fact that it concerns an interval with a time span.

28 It is interesting to compare the states of affairs described in the examples above (It. All'una finalmente Julia si è addormentata, and, of course, Sp. Juan se ha despertado a las tres) and a similar example, It. si è addormentata dolcemente/lentamente/a poco a poco/bruscamente/improvvisamente/di scatto, which is not an externally punctually delimited state of affairs.

29 This is a typical case illustrating the benefits of a frame-based versus a traditional interpretation: if an unequivocal assignment of frapper (which can function as both a semelfactive and a reiterative verb) proves to be problematic for the classic verbal classification, in a model like the one presented here the contextual variants and the polysemies of the verb lexemes can be easily taken into account. Only in the concrete context - in the convergence of various aspectual and non-aspectual contents in the utterance - can we speak of the respective aspectual values of the individual components of the state of affairs or situation frame. In this case, it is the presence of à cinq heures that contributes to a semelfactive interpretation. 
(16) Sp. Explotó [Perf. Sim.] sin hacer ruido. (EA/pd)

'It exploded quietly.'

(17) Cat. El nen va esternudar [Pret. Perf. Per.]. (EA/pd) [anar + Inf.]

'The child sneezed.'

Examples (14)-(17) also express externally delimited states of affairs, i.e., states of affairs that are represented as delimited by a starting point $t_{x}$ and an endpoint $t_{y}$, but here $t_{x}$ and $t_{y}$ coincide. The starting points $t_{x}$ and endpoints $t_{y}$ of the falling asleep of Julia in (14), the knocking on the door by Daniela in (15), the exploding in (16) and the sneezing of the child in (17) are alike insofar as they do not have a duration; or, to put it better, in all the examples they form an interval in which two events are perceived as not being temporally different (i.e., $I=\left|\mathrm{t}_{\mathrm{y}}-\mathrm{t}_{\mathrm{x}}\right|$, where $\mathrm{t}_{\mathrm{x}}=\mathrm{t}_{\mathrm{y}}$; thus $I=\delta \mathrm{t}_{\mathrm{x}}$ ). In examples (14) and (15), moreover, the presence of the temporal, deictic, adverbial determinations all'una and à cinq heures further reinforces the aspectual contents contained in the situation frame. Thus, in these states of affairs an external delimitation of the punctual type can be identified, an EA/pd.

\subsubsection{Externally non-delimited states of affairs (EA/nd)}

Situation frames which do not have an external delimitation can be found in the following examples:

(18) It. La nave approdava [Imp.]. (EA/nd)

'The ship was reaching shore.'

(19) Fr. Marie chante [Prés.] merveilleusement. (EA/nd) $)^{30}$

'Marie sings wonderfully.'

(20) Sp. Mientras Julio comía [Imp.], Carlos hablaba con Marta. (EA/nd)

'While Julio was eating, Carlos was talking to Marta.'

30 This example also shows very clearly how contextualisation of the utterance (i.e., the interpretation of the concretely expressed state of affairs) is essential for determining aspectuality. Example (19) can indeed have different aspectual combination patterns (or delimitation schemas): 1) $[(\mathrm{EA} / \mathrm{nd})+(\mathrm{AA} / \mathrm{nr})+(\mathrm{IA} / \mathrm{ns})]$, when interpreted as a general description of the quality of Marie's singing; 2$)[((\mathrm{EA} / \mathrm{nd})+(\mathrm{AA} / \mathrm{nr})+(\mathrm{IA} / \mathrm{s}))>((\mathrm{EA} / \mathrm{pd})+(\mathrm{AA} / \mathrm{nr})+(\mathrm{IA} / \mathrm{ns}))]$, when it refers to a presentation that is currently taking place. 
(21) Cat. La Rosina sap [Pres.] parlar moltes llengües. (EA/nd) [saber + Inf.] 'Rosina can speak many languages.'

The external aspectuality takes the form of an EA/nd in the states of affairs outlined in (18)-(21), an external non-delimitation. Neither a starting point $t_{x}$ nor an endpoint $t_{\mathrm{y}}$ of the whole state of affairs is focussed here: neither the beginning nor the end of the ship reaching shore in (18); neither the beginning nor the end of the wonderful singing of Marie in (19); neither the beginning nor the end of Julio's eating (and Carlos' and Marta's speaking) in (20) nor Rosina's ability to speak many languages in (21) are in the spotlight. Although (in some of the examples) temporal constitutive moments of the states of affairs can be focussed, ${ }^{31}$ it is their beginning and end which cannot be emphasised. In other words, the delimitation, which therefore represents the completion of the states of affairs, is not presented here: they are states of affairs that are not presented as a whole, in their entirety, and are thus presented as not completed.

\subsubsection{Externally non-delimitable states of affairs (NEA)}

In the following examples, external aspectuality is realised in a very different way: at the abstract, logical level of the impossibility of its determination, and not at the more concrete level of the possibility of its various realisations or basic conceptualisations (such as those in Table (1) and the first part of Table (3)). Indeed, (22)-(25) serve as examples of NEA or nondelimitability (illustrated in the last row of Table (3)), i.e., the impossibility of determining any realisation of external aspectuality:

(22) It. I neonati mangiano [Pres.] e dormono [Pres.]. (NEA) 'Babies eat and sleep.'

(23) Fr. Les hommes sont [Prés.] mortels. (NEA)

'Men are mortal.'

(24) Sp. El tiempo pasa [Pres.]. (NEA)

'Time passes.'

(25) Cat. Els nens creixen [Pres.]. (NEA)

'Children grow up.'

31 See, on this issue, the paragraphs on internal aspectuality below. 
Unlike in all other cases analysed in these paragraphs, in examples (22)-(25) it is in fact impossible to make statements regarding external aspectuality (EA), at least if they are intended and understood as universally valid statements about the world in general. ${ }^{32}$ They are states of affairs that simply are not temporally delimitable, since they lack any kind of external aspectual content, due to their high degree of genericity ${ }^{33}$ that results from the absence of morphological (inflectional) markings of an aspectual nature in combination with the argument structure and pragmatic, i.e., contextual and extralinguistic, information. In other words, we are dealing here with universal valid states of affairs, which are therefore alien to any temporal delimitation: in the eating and sleeping of the babies in (22), in the being mortal of the people in (23), in the passing of time in (24) or in the growing of the children in (25), there are no aspectual markings on the predicate (which is expressed in the present tense), nor can we find contents that would allow for an aspectual delimitation in the first argument of each example (i.e., i neonati, les hommes, el tiempo and els nens, which include all babies and all people in the world and in the course of time, i.e., representing the whole class of these individuals). In these particular constructions, in these situation frames, $i$ neonati, les hommes, el tiempo and els nens express no individual reference, but rather genericity: they refer to classes of individuals - or to abstract nouns, as in the case of el tiempo. Here it also becomes particularly clear the great influence of the subject, which as a noun normally does not carry aspectual information, on the interpretation of the frame.

It is logical that all situation frames that are non-delimitable, i.e., cannot be delimited (NEA), are also de facto non-delimited (while of course this is not true the other way around). The fact that there is nevertheless an external aspectual difference between situation frames that have an EA/nd and those that

32 This is not contradicted by the fact that the same sentences can be statements about concrete individual states of affairs in the case of a concrete realisation in a different frame. Interpretation of example (22) varies so much that - depending on the concrete situation frame or state of affairs in which it is realised - very different combinations of the dimensions of aspectuality can result: 1) the state of affairs presented in (22) is understood and used as a generally valid statement about the world in general (all components of the frame are generic in such a case); 2) the state of affairs described in (22) is interpreted as a special statement by a paediatric nurse who, at the end of a long and tiring day, reports the situation of the ward when handing it over to a colleague (in which case the components of the frame are not generic).

33 On genericity in general see Carlson (2005) and Carlson/Pelletier (1995). 
have an NEA can be better explained by comparative analysis of the following cases:

(26) It. Leo è [Pres.] rosso di capelli. (EA/nd)

'Leo is red haired.'

(26') It. Leo era [Imp.] rosso di capelli. (EA/nd)

'Leo was red haired.'

(27) Fr. Daniel est [Prés.] architecte. (EA/nd)

'Daniel is an architect.'

(27’) Fr. Daniel était [Imp.] architecte. (EA/nd)

'Daniel was an architect.'

(28) Sp. Marta tiene [Pres.] miedo de la lluvia. (EA/nd)

'Marta is afraid of the rain.'

(28') Sp. Marta tenía [Imp.] miedo de la lluvia. (EA/nd)

'Marta was afraid of the rain.'

(29) Cat. És [Pres.] una dona romàntica i maquísima. (EA/nd)

'She's a romantic and very beautiful woman.'

(29') Cat. Era [Imp.] una dona romàntica i maquísima. (EA/nd)

'She was a romantic and very beautiful woman.'

(30) It. I neonati mangiano [Pres.] e dormono [Pres.]. (NEA)

'Babies eat and sleep.'

(30') It. I neonati mangiavano [Imp.] e dormivano [Imp.]. (EA/nd)

'The babies were eating and sleeping.'

(31) Fr. Les hommes sont [Prés.] mortels. (NEA)

'Men are mortal.'

(31') Fr. Les hommes étaient [Imp.] mortels. (EA/nd)

'The men were mortal.' 
(32) Sp. El tiempo pasa [Pres.]. (NEA)

'Time passes.'

(32') Sp. El tiempo pasaba [Imp.]. (EA/nd)

'The time was passing.'

(33) Cat. Els nens creixen [Pres.]. (NEA)

'Children grow up.'

(33’) Cat. Els nens creixien [Imp.]. (EA/nd)

'The children were growing up.'

In the first example pairs (26/26')-(29/29'), the absence of morphological temporal-aspectual markings in the examples expressed in the present tense, (26)-(29), or their presence (in examples (26')-(29') through the various Romance imperfect forms) has no influence on the realisation of external aspectuality, which is always EA/nd. Whether an ideal she (a personal pronoun standing for a particular individual and not for a class of individuals) is now romantic and beautiful or used to be, both cases represent a state of affairs that is not perceived as a completed whole (one cannot identify a $t_{x}$ in which she began to be romantic and beautiful, nor a $t_{y}$ in which she stopped being so), i.e., as a state of affairs that is thus not externally delimited.

On the other hand, in the other example pairs (30/30')-(33/33'), the absence of morphological temporal-aspectual markings in examples (30)-(33) expressed in the present tense or their presence (in examples (30')-(33') expressed through the various Romance imperfect forms) play an important role in the constitution of external aspectuality in the respective situation frames. Examples (30')-(33') all represent cases of EA/nd, like (26/26')-(29/29') above. For example, in (30’) it is not possible to identify $a t_{x}$ in which the babies (and here it is recognisable from the past tense that these must be some particular babies and not the entire class of babies) began to eat and sleep (here in the imperfect and not the present tense), nor a $t_{y}$ in which they stopped doing so. Similarly, in example (32') time must be a particular time (the time of a life, the time available to a person for a particular act, etc.) and not the extralinguistic, not further defined, eternal flowing time that regulates the destinies of the world and people, ${ }^{34}$ and that time passed (morphologically marked by the imperfect) without us being able to

34 In the absence of any further determination, the reference to this prototypical physical time is established, understood as an implicature, as in example (32). 
identify a $t_{x}$ or a $t_{y}$ delimiting the beginning and ending of that passing. Again, this is a typical example of an externally non-delimited state of affairs.

However, it should be emphasised here once again that it is not just the morphological aspectual marking (in these examples, the presence of the respective Romance forms of the imperfect) that is solely responsible for the indeterminability of the external aspectuality and therefore for the entire aspectual interpretation of the situation frame or the state of affairs. As has been shown, the degree of genericity of the respective arguments of the verb also plays an essential role.

\subsubsection{Adjacency-related aspectuality - adjacency relevance of the state of affairs}

In the case of adjacency-related aspectuality (AA), the relevance of the state of affairs for its adjacency - that which temporally lies before and after the state of affairs and which can be represented as an interval $I=\left|\mathrm{t}_{\mathrm{y}}-\mathrm{t}_{\mathrm{x}}\right|-$ is focussed, while its structuring and delimitation recede into the background. The AA is subdivided into four realisations, four different basic conceptualisations:

- A state of affairs can be relevant to its adjacency as a final delimitation (AA/fr); in this case, it is a state of affairs that has an influence on the structuring of its adjacency by functioning as a final delimitation of its previous adjacency: it thus determines its end.

- A state of affairs can be relevant to its adjacency as an initial delimitation (AA/ir); in this case, it is a state of affairs that has an influence on the structuring of its adjacency by functioning as the initial delimitation of its subsequent adjacency: it determines its beginning.

- A state of affairs can be relevant to its adjacency as a final and an initial (i.e., transformative) delimitation (AA/tr); in this case, it is a state of affairs that has an influence on the structuring of its adjacency, namely by exerting an influence on its previous and subsequent adjacency as a final delimitation and as an initial delimitation: it determines its beginning and end, thus entailing a transformation, a change of state.

- A state of affairs can be irrelevant to its adjacency (AA/nr); in this case, it is a state of affairs that has no influence on the structuring of its adjacency, neither as an initial nor as a final delimitation.

Table (4) illustrates the different realisations of AA (with the state of affairs and its delimitation highlighted in light grey, while the adjacency which the state of 
affairs influences or for which it is relevant is black in the first row, dark grey in the second):

Tab. 4: Adjacency-related aspectuality.

AA- Adjacency-related Aspectuality
adjacency relevance of a state of affairs (SA)

In the case of $\mathrm{AA}$, too, there is another possibility that does not correspond to any of the basic conceptualisations presented above, but relates to a more abstract level of adjacency-related non-delimitability (NAA) (see the last row of Table (4)). There are aspectual situation frames, i.e., special delimitation constructions, where no statement regarding AA is possible. These are cases that are not contextually delimitable, when a state of affairs is not externally delimited or - more abstractly - not delimitable, so that if it has an external delimitation of the type EA/nd or NEA, it can logically have no effect on its adjacency, because the latter cannot exist without a boundary (and therefore, of course, it cannot be relevant for such an (inexistent) adjacency).

Of the various examples and example types that could be cited for the realisations of adjacency-related aspectuality - in particular AA and NAA - the following are a first selection and, as in the case of external aspectuality, a few of them will be briefly discussed below. 


\subsubsection{States of affairs with final relevance to adjacency (AA/fr)}

Let's take a look at the following examples:

(34) It. Il sole è appena tramontato [Perf. Com.]. (AA/fr)

'The sun has just set.'

(35) Fr. Marie-Rose vient [Prés.] de chanter. (AA/fr) [venir de + Inf.] 'Marie-Rose has just sung.'

(36) Sp. Juan se comió [Perf. Sim.] su osito de gominola con gran gusto. (AA/fr) 'Juan ate his jelly baby with great delight.'

(37) Cat. Acabo [Pres.] de parlar amb el president de la república italiana. (AA/fr) [acabar de + Inf.]

'I have just spoken to the President of the Italian Republic.'

When dealing with aspectuality from the adjacency-related perspective, as it appears in the states of affairs expressed in examples (34)-(37), it should be noted that all these examples are cases of AA/fr, in other words, states of affairs that have an influence on the structuring of their adjacencies insofar as they function as a final delimitation of their previous adjacency and represent its end.

When analysing the examples in more detail, one can further say that the facts shown in (34) and (35) - i.e., that the sun has just set and Marie-Rose has just sung - as well as Juan's pleasurable eating of a jelly baby in (36) and the conclusion of the conversation with the President of the Italian Republic in (37) present states of affairs that are relevant to their adjacencies in a particular way. That the sun has just set means that it no longer shines in the sky (and also that it is no longer possible a) that it continues to shine, b) that it continues to go down). Similarly, the fact that Juan has eaten his jelly baby means that the jelly baby is no more at the end of the process. With this disappearance, both the continuation of the process (he cannot continue eating the jelly baby) and the reversal of the state of affairs are impossible. Similarly, the fact that I have just finished my conversation with the Italian President determines that I am no longer talking to him now. In both cases, the previous adjacency of the state of affairs has been finished by the state of affairs itself. 


\subsubsection{States of affairs with initial relevance to adjacency (AA/ir)}

Among the examples that express states of affairs with initial adjacency-related relevance, the following should be analysed in more detail:

(38) It. Il sole sta [Pres.] per sorgere silenzioso. (AA/ir) [stare per + Inf.] 'The sun is about to rise quietly.'

(39) Fr. Petit à petit Julie se met [Prés.] à chanter. (AA/ir) [se mettre à + Inf.] 'Little by little Julie starts singing.'

(40) Sp. Juan comienza [Pres.] a despertarse. (AA/ir) [comenzar a + Inf.] 'Juan begins to wake up.'

(41) Cat. La lluna terrestre es va formar [Pret. Perf. Per.] més tard que la resta del sistema solar. (AA/ir) [anar + Inf.]

'The Earth's moon formed later than the rest of the solar system.'

Considering aspectuality from the adjacency-related perspective, as it appears in the states of affairs expressed in (38)-(41), we find that these represent cases of AA/ir. These are therefore states of affairs which have an influence on the structuring of their adjacencies insofar as they function as an initial delimitation of their subsequent adjacency and they therefore represent its beginning.

The fact expressed in (38) that the sun is about to rise quietly, as well as what is expressed in (39), (40) and (41), respectively, that Julie slowly begins to sing, that Juan begins to awaken, and that the moon was formed after the rest of the solar system, all represent states of affairs that are relevant to their adjacencies in a special way. That the sun is about to rise quietly means that at the end of the process the sun will rise (which was not the case before the beginning of this process). Similarly, the fact that the moon was formed after the rest of the solar system means that it will continue to exist after the process of creation (i.e., after the end of the state of affairs itself). In all the cases discussed, the subsequent adjacency of the states of affairs begins with the respective state of affairs.

\subsubsection{States of affairs with initial and final (transformative) relevance to adjacency (AA/tr)}

States of affairs that have both initial and final adjacency-related relevance can be illustrated by the following examples: 
(42) It. Leo arrossisce [Pres.] davanti a Julia. (AA/tr)

'Leo blushes in front of Julia.'

(43) Fr. Le printemps s'installa [Pass. Sim.] dans les jardins tout doucement. (AA/tr)

'Spring came to the gardens very slowly.'

(44) Sp. Las ventas de la pastelería aumentan [Pres.]. (AA/tr)

'Bakery sales are increasing.'

(45) Cat. Xavier cada dia està [Pres.] més boig. (AA/tr)

'Xavier gets more and more crazy every day.'

Considering the adjacency-related aspectuality of the states of affairs expressed in (42)-(45), it can be seen that these are cases of final and initial adjacencyrelated relevance $(\mathrm{AA} / \mathrm{tr})$, or states of affairs that are relevant for their entire adjacency by representing the end of the previous and the beginning of the subsequent adjacency in relation to a coherent complex of state of affairs. In other words, they function as state-changing states of affairs. ${ }^{35}$

The fact that in (42) Leo blushes when looking at Julia, determines the end of the previous adjacency in which Leo still had a normal complexion, and marks the beginning of the subsequent one, in which blush of shame shows in Leo's face. Similarly formed is the adjacency-related aspectuality in example (43): spring slowly coming to the garden determines the end of the winter state of the garden and the beginning of spring. The states of affairs presented in examples (44) and (45) warrant a similar analysis: that the turnover of baked goods (or the degree of Xavier's craziness) increases determines the end of the previous adjacency in which there was a lower turnover (or degree of craziness), and marks the beginning of the subsequent one where it is greater.

\subsubsection{States of affairs without relevance to adjacency (AA/nr)}

Finally, situation frames without adjacency-related aspectuality can be illustrated by the following examples:

35 Interesting in this regard is the comparison between the Romance languages and German. Both tend to express this aspectual building block by special - derivational - morphological means: the Romance languages by the so-called parasynthesis (e.g., It. arrossire, invecchiare, Sp. engordarse) and German by prefixation (e.g., umziehen, umfärben, umdrehen). 
(46) It. Leo esce [Pres.] da casa e fa [Pres.] un giro sulla bicicletta nuova. (AA/nr) 'Leo leaves the house and goes for a ride on his new bike.'

(47) Fr. À cinq heures Béatrice frappe ${ }^{36}$ [Prés.] à la porte. (AA/nr)

'At five o'clock Béatrice knocks on the door.'

(48) Sp. El oso polar se acarició [Perf. Sim.] su hermoso pelo con gracia glacial. (AA/nr)

'The polar bear stroked its beautiful fur with glacial grace.'

(49) Cat. En Jordi va parlar [Pret. Perf. Per.] amb la Pili. (AA/nr) [anar + Inf.] 'Jordi talked to Pili.'

A closer analysis of the examples (46)-(49) from the perspective of adjacencyrelated aspectuality shows that in all cases these are states of affairs of the type $\mathrm{AA} / \mathrm{nr}$. In other words, they are states of affairs that have absolutely no influence on the structuring of their adjacencies: they are completely irrelevant to their respective adjacencies insofar as they do not determine either the beginning nor the end of any other state of affairs in their adjacencies.

Closer analysis of the above examples reveals that all four of the states of affairs presented - Leo's little ride with his new bike in (46), Béatrice's knocking on the door at 5 o'clock in (47), the polar bear's graceful stroking of its beautiful fur (48), as well as the speaking of Jordi to Pili in (49) - have no relevance for the time before and time after the ride on the new bike, the knocking, the stroking and the speaking. In all cases, the states of affairs do not in any way influence their previous and subsequent adjacencies, nor do they determine any beginning or end of other states of affairs of the adjacencies.

\subsubsection{Adjacency-related non-delimitable states of affairs (NAA)}

Adjacency-related aspectuality is treated on another level in the examples below: the abstract level of the impossibility of determining it, and not the more concrete possibility of its realisations or basic conceptualisations in the various situation frames (see the first part of Table (4) and the previous analysis). Indeed, (50)-(57) serve rather to exemplify NAA or the non-delimitability of adjacency relevance (see the last row of Table (4)), i.e., the impossibility of

36 The interpretation of this example also poses some problems for the traditional verb classification which analyses the elements on their own and not in the context of a frame, as frapper (here 'to knock'), considered on its own, has both a semelfactive and a reiterative component. 
determining the presence or absence of any realisation of adjacency-related aspectuality:

(50) It. I neonati mangiano [Pres.] e dormono [Pres.]. (NAA)

'Babies eat and sleep.'

(51) It. Leo ha [Pres.] i capelli rossi. (NAA)

'Leo has red hair.'

(52) Fr. Les hommes sont [Prés.] mortels. (NAA)

'Men are mortal.'

(53) Fr. Julie était [Imp.] grande. (NAA)

'Julie was tall.'

(54) Sp. Pablo era [Imp.] un gran gato, de pelo corto de color naranja y blanco. (NAA)

'Pablo was a great cat, with short orange and white hair.'

(55) Sp. El tiempo pasaba [Imp.]. (NAA)

'The time was passing.'

(56) Cat. Els nens creixen [Pres.]. (NAA)

'Children grow up.'

(57) Cat. La Rosina sap [Pres.] parlar moltes llengües. (NAA) [saber + Inf.]

'Rosina can speak many languages.'

Unlike all the other cases analysed in paragraphs 4.4.4.1-4.4.4.4, it is impossible to make any statement regarding adjacency-related aspectuality with respect to examples (50)-(57). These are very different states of affairs, which in part should be considered here from more than one aspectual perspective:

- On the one hand, these are states of affairs that are either not delimited (i.e., EA/nd realisations as in (51), (53), (54), (55) and (57)), which includes the cases that are not delimitable (and therefore realisations of NEA as in (50), (52) and (56)). ${ }^{37}$ By way of example, we can analyse in detail (51) (in

37 Of course, in particular interpretation contexts, states of affairs such as these may be interpreted differently in terms of aspectuality. See on this issue §4.4.3.4. 
which no moment $t_{x}$ in which Leo begins to have red hair can be focussed, nor any moment $\mathrm{t}_{\mathrm{y}}$ in which he stops), or (50) in which - as mentioned above - the eating and sleeping of the babies bear neither aspectual markings on the predicate nor contents in the first argument of each example that would allow for an aspectual delimitation. In fact, in this type of state of affairs - due to the absence of a form of delimitation of the state of affairs as a whole - there is no adjacency-related aspectual content. For logical reasons, the absence of temporal boundaries excludes the possibility of determining its adjacency: without a temporal delimitation, without an interval $I=\left|\mathrm{t}_{\mathrm{y}}-\mathrm{t}_{\mathrm{x}}\right|$, there can be no before or after this delimitation.

- On the other hand, these are also states of affairs that are not internally subdivided and hence realise the internal aspectuality of type IA/ns, as found in examples (51), (53), (54) and (57) (which includes cases that are not subdivisible and are therefore realisations of NIA (see §4.4.5.3), as in (50), (52) and (56)). For, if a state of affairs is monophasic, if no constitutive, individually isolable phases (or points in time $t_{x 1}, t_{x 2}, \ldots t_{x n}$ ) can be identified within it, which in turn are nothing other than the setting of temporal boundaries, then there is no possibility of a variation in time, dynamicity, because this consists precisely in the possibility of a change of state, the beginning and ending of intervals in the state of affairs. And where no discrete temporal subintervals can be identified, as is the case with states of affairs that are not internally subdivided, there can be no change in time nor at its boundaries, and thus there can be no aspectual adjacency reference. Here, too, we can take a closer look at example (51), in which no moment $t_{\mathrm{y}}$ different from the other moments of Leo's having-red-hair can be focussed (just as no beginning or end of having red hair is focussed).

In this case, too, it follows logically that all situation frames that are nondelimitable in terms of adjacency (NAA) are also non-delimited in terms of their adjacency relevance $(\mathrm{AA} / \mathrm{nr})$.

\subsubsection{Internal aspectuality - subdivision of the state of affairs}

In the case of internal aspectuality (IA) the focus is on the structuring of the state of affairs, i.e., the possible realisations of the subdivision of a state of affairs, regardless of its (external) delimitation and its adjacency reference, which recede into the background. Two realisations of IA can be distinguished: 
- A state of affairs may be internally subdivided (IA/s); in this case it is a state of affairs that is internally temporally subdivided and is therefore pluriphasic. Between $t_{x}$ and $t_{y}$ of the interval $I=\left|t_{y}-t_{x}\right|$ (i.e., between the delimitation points, which can be given if the state of affairs has an external delimitation (EA/d)), but also generally in the temporal structure of the state of affairs, if it is a state of affairs without external delimitation $(\mathrm{EA} / \mathrm{nd})$, there are other points $\mathrm{t}_{\mathrm{x} 1}, \mathrm{t}_{\mathrm{x} 2}, \ldots \mathrm{t}_{\mathrm{xn}}$ into which the state of affairs can be subdivided.

- A state of affairs can be internally non-subdivided (IA/ns); in this case, it is a homogeneous, internally temporally not further subdivided state of affairs, i.e., it is monophasic: between a starting point $t_{x}$, possibly focussed in the external aspectuality, and an endpoint $\mathrm{t}_{\mathrm{y}}$ or within the externally non-delimited state of affairs, no further points $t_{x 1}, t_{x 2}, \ldots t_{x n}$ can be identified into which the temporal development of the state of affairs in general may be subdivided.

Table (5) illustrates the various realisations of IA (the state of affairs in its internal structuring is black in the first row of the table, dark grey in the second row, and its delimitation and adjacency are shown in light grey):

Tab. 5: Internal aspectuality.
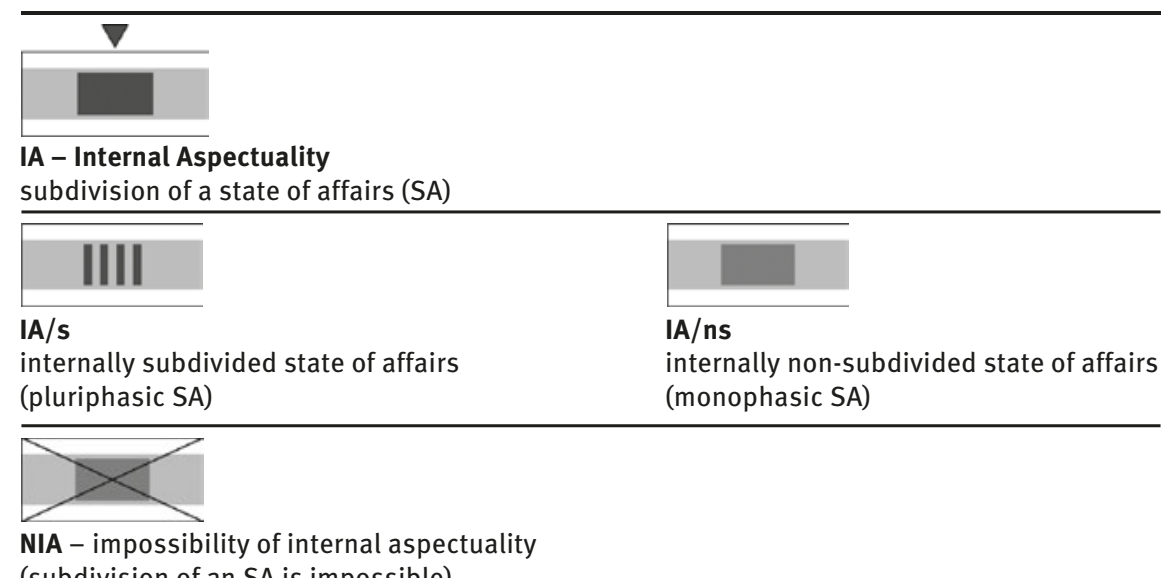

(subdivision of an SA is impossible)

As with the other two perspectives of aspectuality, in the case of IA there is another possibility for the realisation or non-realisation of aspectual content (see the last row of Table (5)). This does not represent two possible realisations, 
but concerns a more abstract level of non-subdivisibility: there are indeed states of affairs where (in particular delimitation constellations) no statement regarding IA is possible. These are cases of NIA which, for logical reasons, cannot be determined in terms of internal aspectuality, as is the case with constructions that have external punctual aspectuality (EA/pd). When dealing with an externally delimited state of affairs whose initial boundary $t_{x}$ coincides with its final boundary $t_{y}\left(t_{x}=t_{y}\right)$, it is impossible to postulate the existence of further points $t_{x 1}, t_{x 2}, \ldots t_{x n}$ (i.e., a period of time) in the state of affairs into which the interval comprising the state of affairs $I=\left|t_{y}-t_{x}\right|$ can be subdivided, because the interval is perceived as so small that we can speak of a single point (without temporal extension). And what is presented without temporal extension cannot logically be subdivided into further temporal delimitations or subintervals.

As done above for external and adjacency-related aspectuality, let us first comment on some examples of the two realisations of IA and of NIA.

\subsubsection{Internally subdivided states of affairs (IA/s)}

Let us consider the following examples:

(58) It. Leo mangia [Pres.] un cornetto al cioccolato con evidente soddisfazione. (IA/s)

'Leo is eating a chocolate croissant with obvious satisfaction.'

(59) Fr. Julie a frappé [Pass. Com.] à la porte maintes et maintes fois. (IA/s)

'Julie knocked on the door over and over again.'

(60) Sp. Juan duerme/dormía [Pres./Imp.] con un ojo abierto. (IA/s) 'Juan is sleeping/was sleeping with one eye open.'

(61) Cat. La Rosina escriu [Pres.] una novel-la fantàstica. (IA/s)

'Rosina is writing a fantastic novel.'

When focussing on internal aspectuality, as expressed in the states of affairs in (58)-(61) - i.e., on the possible subdivision of these states of affairs - it can be stated that all the examples are internally subdivided states of affairs (IA/s), i.e., they are pluriphasic. On the level of internal aspectuality, various constitutive intervals or points of time $\left(t_{x 1}, t_{x 2}, \ldots t_{x n}\right)$ can be identified (irrespective of whether the state of affairs is delimited or not). There are several (substantially) different moments $t_{x 1}, t_{x 2}, \ldots t_{x n}$ in Leo's eating of a croissant (58), in Julie's 
repeated knocking on the door (59), in Juan's sleeping with one eye open (60), and in Rosina's writing a fantastic novel (61). Leo eats (or Julie knocks on the door, Juan sleeps or Rosina writes a novel) in $t_{x 1}$, just as he (or she) eats (knocks, sleeps or writes) in $t_{x 2}$ and $t_{x 3}, t_{x n} \ldots$, and these single moments can be separated and focussed on as being different from each other. All these states of affairs consist of different phases, discrete moments $t_{x 1}, t_{x 2}, \ldots t_{x n}$, which, since they can be individually focussed on, allow for the perception of dynamicity.

\subsubsection{Internally non-subdivided states of affairs (IA/ns)}

Situation frames that, on the other hand, are not subdivided can be seen in the following examples:

(62) It. Leo ha [Pres.] i capelli rossi. (IA/ns)

'Leo has red hair.'

(63) Fr. Je suis [Prés.] très petite. (IA/ns)

'I am very small.'

(64) Sp. Marta tiene [Pres.] miedo de la lluvia. (IA/ns)

'Marta is afraid of the rain.'

(65) Cat. La Rosina sap [Pres.] parlar moltes llengües. (IA/ns) [saber + Inf.] 'Rosina can speak many languages.'

If we consider the internal aspectuality expressed in the states of affairs presented in (62)-(65), i.e., their subdivision, we can say that all the examples are internally non-subdivided states of affairs (IA/ns), i.e., they are monophasic. On the level of internal aspectuality, here we cannot identify any structuring, any constitutive phases (or points of time $t_{x 1}, t_{x 2}, \ldots t_{x n}$ ) that can be individually isolated and focussed. In other words, there are no (substantially) different moments $t_{x 1}, t_{x 2}, \ldots t_{x n}$ (which thus cannot be focussed) in the fact that Leo has red hair (62), that I am very small (63), that Marta is afraid of the rain (64), or that Rosina can speak many languages (65). ${ }^{38}$

38 As a brief reminder, internal aspectuality includes the criterion of dynamicity/stativity; see $\S 4.4 .1$ for more details. 


\subsubsection{Internally non-subdivisible states of affairs (NIA)}

In the following examples - as above with external and adjacency-related aspectuality - internal aspectuality is finally also dealt with on a more abstract level, namely, that of the impossibility of its determination. The following examples (66)-(69) should therefore serve to exemplify NIA or non-subdivisibility (see the last row in Table (5)), i.e., the impossibility of determining the presence or absence of any realisation of internal aspectuality:

(66) It. La nave dell'ammiraglio approdò [Perf. Sem.] alle tre e un quarto. (NIA) 'The admiral's ship reached shore at 3:15.'

(67) Fr. Il toussa [Pass. Sim.] fort une seule fois. (NIA) 'He coughed hard only once.'

(68) Sp. Explotó [Perf. Sim.] sin hacer ruido. (NIA) 'It exploded quietly.'

(69) Cat. El príncep truca [Pres.] tímid a la porta del castell. (NIA) 'The prince knocks shyly on the door of the castle.'

(70) It. I neonati mangiano [Pres.] e dormono [Pres.]. (NEA) 'Babies eat and sleep.'

(71) Fr. Les hommes sont [Prés.] mortels. (NEA) 'Men are mortal.'

(72) Sp. El tiempo pasa [Pres.]. (NEA) 'Time passes.'

(73) Cat. Els nens creixen [Pres.]. (NEA) 'Children grow up.'

Unlike all the other concrete realisations or basic conceptualisations of internal aspectuality analysed in $\S \S 4.4 \cdot 5.1-4.4 .5 .2$, it is impossible in the cases of (66)-(73) to make any statement regarding internal aspectuality. These are very different states of affairs, which in part should be considered here from more than one aspectual perspective:

- On the one hand, these are states of affairs that are not temporally subdivisible due to their punctual constitution, their lack of a perceptible temporal extension. In examples (66)-(69), the initial boundary $t_{x}$ (the moment 
when the ship reaches shore, in which he coughs once, in which something exploded quietly and in which the prince shyly knocks on the door of the castle) coincides with the final boundary $t_{y}$ (precisely the moment when the ship reaches shore, when he coughs once, when something exploded quietly and when the prince shyly knocks on the door of the castle). It is therefore impossible to postulate the existence of further points $t_{x 1}$, $\mathrm{t}_{\mathrm{x} 2}, \ldots \mathrm{t}_{\mathrm{xn}}$ in the state of affairs in which the interval $I=\left|\mathrm{t}_{\mathrm{y}}-\mathrm{t}_{\mathrm{x}}\right|$ with $\mathrm{t}_{\mathrm{y}}=\mathrm{t}_{\mathrm{x}}$ that represents the delimited state of affairs could be subdivided. Thus, the temporally barely perceivable interval (precisely the smallest possible interval of the length $\delta t_{x}$ of, for example, the quiet exploding) could not by definition be further subdivided.

- On the other hand, these are states of affairs of the type NEA and NAA, as in examples (70)-(73).

Logically, what has already been stated for external and adjacency-related aspectuality also applies to internal aspectuality: states of affairs that are not subdivisible (NIA) are also internally non-subdivided (IA/ns).

\subsection{A second interim conclusion}

In this chapter, the first steps have been taken to introduce a new unidimensional model of aspectuality. On the basis of the cognitive principle of delimitation, the definition of aspectuality - the content category by which speakers linguistically structure the internal nature of the development and distribution of a given state of affairs in time - was further clarified: namely as a content category through which speakers express the possibilities of external, adjacency-related and internal temporal structuring of states of affairs.

The various realisations of the three dimensions of aspectuality, the aspectual basic conceptualisations, were presented here individually and illustrated with examples, which were, however, analysed only in relation to the perspective under consideration, while the other two dimensions were disregarded in order to provide a better understanding of the model. In the overall aspectual meaning of a situation frame, however, several perspectives of aspectuality and hence several aspectual basic conceptualisations are always connected to each other. It will now be my task in the next chapter to present the entire aspectual structuring of states of affairs perceived as situation frames, i.e., the possibilities of combining aspectual content in the constitution of the overall aspectual meaning of states of affairs. 
